\title{
IMPLEMENTASI PROCESS MINING DENGAN METODE PROCESS DISCOVERYSTUDI KASUS PADA APLIKASI INTEGRATED FLEXIBLE LEARNING EXPERIENCE (IFLEX)
}

\author{
Lugina Suciati Putri, Gadang Ramantoko \\ Fakultas Ekonomi dan Bisnis Universitas Telkom \\ Jalan Telekomunikasi No. 1, Bandung \\ ginagina@student.telkomuniversity.ac.id
}

\begin{abstract}
IFLEX launches its first version of MVP for IndiHome technicians. But there are some flaws in the validation method that performed on the first version of MVP so that it requires an alternative method of validation that is measurable and needs to be implemented since the start to be able to validate many users in the future. Therefore, process mining is applied to the second version of MVP as an alternative validation method on the pre-login/preregister process. Process mining with process discovery method using the Celonis Snap application is able to produce the actual process model occurred by utilizing data from the IFLEX's event log recorded from 13 March 2020 to 13 April 2020 on the implementation of the sprint 1 whose users are registered as Telkom employees in Medan. The process model simplifies process analysis on pre-login/Pre-register pages.

There are 563 activities with the 43 case ids on data from the event log. After filtered, 26 case ids are obtained in pre-login/pre-register process. From this data, a process model with various visualizations is obtained. Up to 5 main activities (Onboarding 1, Login, email input for login, input password for login and try login), average users time complete the process (92 seconds), three subprocesses (application introduction, register and login) and the time of each activities. The findings became the basis for IFLEX to conduct further research on the effectiveness and efficiency.
\end{abstract}

Keywords: processes, process mining, process discovery, process model, activity

\begin{abstract}
Abstrak
IFLEX meluncurkan MVP versi pertama untuk pengguna yang merupakan Teknisi IndiHome. Namun terdapat beberapa kekurangan pada metode validasi ang dilakukan pada MVP versi pertama sehingga memerlukan alternatif metode validasi yang terukur dan perlu diterapkan sejak awal sebagai persiapan untuk bisa memvalidasi banyak jumlah pengguna di kemudian hari. Maka dari itu process mining diterapkan pada MVP versi kedua sebagai alternatif metode validasi pada proses pre-login/pre-register. Process mining dengan metode process discovery menggunakan aplikasi Celonis Snap mampu menghasilkan model proses yang sebenarnya terjadi dengan memanfaatkan data dari event log aplikasi IFLEX yang tercatat dari 13 Maret 2020 hingga 13 April 2020 pada penerapan hasil sprint 1 yang penggunanya merupakan karyawan Telkom Medan. Model proses tersebut mempermudah analisis proses pada halaman pre-login/pre-register.

Terdapat 563 aktivitas dengan 43 case id pada data dari event log. Setelah disaring, didapatkan 26 case id pada proses pre-login/pre-register. Dari data tersebut didapatkan model proses dengan berbagai visualisasi. Dapat diketahui 5 aktivitas utama (Onboarding 1, Login, input email for login, input password for login dan try login), waktu rata-rata pengguna menyelesaikan proses (92 detik), tiga subproses (perkenalan aplikasi, register dan login) dan waktu dari tiap aktivitas. Temuan tersebut dijadikan dasar agar IFLEX melakukan penelitian lebih lanjut untuk efektifitas dan efisiensi.
\end{abstract}

Kata Kunci: proses, process mining, process discovery, model proses, aktivitas

\section{Pendahuluan}

Aplikasi Integrated and Flexible Learning

Experience (IFLEX) merupakan multimedia mobile kearning application yang diciptakan untuk membantu karyawan Telkom dalam berbagi dan berdiskusi mengenai suatu 
masalah dan solusinya (IFLEX, 2019). IFLEX memiliki kelebihan pada sistem belajar dua arah yang dapat diakses oleh semua pengguna IFLEX sehingga memungkinkan penyebaran ilmu teoritis dan praktis lebih luas dan cepat juga terciptanya ruang diskusi dua arah untuk semua pengguna pada forum yang bersifat tertutup yang hanya dapat diakses oleh perusahaan menjadikan IFLEX lebih unggul dibandingkan platform lainya (IFLEX, 2019).

IFLEX meluncurkan MVP versi pertama untuk pengguna yang merupakan teknisi IndiHome. Versi pertama ini telah mendapatkan 26 early adapter, namun mendapatkan banyak respon balik terkait kekurangan dan kesulitan penggunaan aplikasi yang disampaikan melalui komunikasi langsung, dan validasi melalui dua cara, yaitu: usability testing, dan wawancara.

Kedua metode validasi ini dilakukan kepada pengguna yang dipilih secara acak. Setiap proses validasi direkam, metode usability testing dengan merekam layar ponsel pengguna dan metode wawancara direkam menggunakan perekam suara. Setiap pengguna yang dipilih diminta untuk mengutarakan pendapat dan kesulitannya menggunakan aplikasi IFLEX. Kedua metode ini memiliki kelebihan yaitu mendapatkan informasi penggunaan aplikasi dari sudut pandang Teknisi. Namun ada pula kekurangan dari kedua metode ini, yaitu:

1. Respon pengguna yang terpilih secara acak belum tentu mewakili keseluruhan pengguna.

2. Tidak semua pengguna dapat mengutarakan pendapatnya dengan baik dan jujur.

3. Pelaksanaan validasi memerlukan ketersediaan waktu pengguna

4. Perlu ada gimmick agar pengguna bersedia divalidasi.

5. Tidak scalable, karena memerlukan waktu, tenaga manusia dan biaya untuk melakukannya.

Berbagai kekurangan ini memerlukan alternatif metode validasi yang terukur dan perlu diterapkan sejak awal sebagai persiapan untuk bisa memvalidasi banyak jumlah pengguna di kemudian hari

Pada Agustus 2019, aplikasi IFLEX mendapatkan dukungan Telkom Corporate University untuk menerapkan platform pembelajaran ini kepada karyawan Telkom, dimulai dengan karyawan Telkom di Medan sebagai early adapter. Selain itu, IFLEX diminta untuk menerapkan sprint development dengan metode scrum. Perubahan target pengguna dan metode pengembangan mengakibatkan IFLEX perlu dibangun dari awal dan membuat MVP versi kedua. Penerapan sprint development membuat pengembangan IFLEX dipecah menjadi beberapa bagian kecil pengembangan aplikasi yang disebut sprint.

Business Process Management (BPM) adalah sebuah prinsip, metode dan alat yang mampu digunakan untuk menemukan, menganalisis, mendesain ulang, mengimplementasikan dan memantau proses bisnis (Dumas et al., 2018). Dalam artian lain, BPM bertujuan untuk menciptakan optimalisasi pada sebuah proses bisnis. BPM memiliki keterkaitan dengan Process Mining yaitu menjadi jembatan antara monitoring phase, discovery phase dan analysis phase pada BPM Lifecycle (Dumas et al., 2018). Process mining pada dasarnya digunakan untuk menemukan, memonitor dan meningkatkan proses yang sebenarnya terjadi dengan cara mengolah data dari event logs (Aalst, 2016). Process discovery merupakan salah satu metode dari process mining yang berfungsi untuk menghasilkan model proses yang sebenarnya terjadi (Aalst, 2016). Model proses yang dihasilkan oleh metode ini dapat memperlihatkan bagaimana perilaku yang terjadi pada proses (Aalst, 2016).

Teknik process mining pada BPM dapat mempermudah IFLEX untuk menciptakan optimalisasi proses bisnis pada aplikasinya. Penelitian ini berfokus pada penerapan teknik process mining dengan metode process discovery yang dapat membantu IFLEX pada MVP keduanya untuk menghasilkan model proses pada aplikasinya sehingga proses yang sebenarnya terjadi dapat diketahui. Dalam penelitian ini, process mining diterapkan pada sprint 1 yang berupa proses pra-login/praregister aplikasi IFLEX. Tujuan dari penelitian ini adalah untuk mengetahui model proses, aktivitas, waktu dan hambatan pada proses pra-login/pra-register IFLEX.

\section{Business process}

Dumas et al. (2018) menjabarkan bahwa proses adalah seluruh rantai peristiwa, aktivitas dan keputusan. Peristiwa pada proses 
adalah sesuatu yang terjadi secara otomatis dan tidak memiliki durasi. Peristiwa dapat memicu pelaksanaan serangkaian aktivitas dan tiap aktivitas membutuhkan waktu. Di beberapa proses terdapat titik keputusan yang mana di saat sebuah keputusan dibuat, keputusasn tersebut dapat mempengaruhi pelaksanaan proses tersebut. Dumas et al. (2018) juga menyatakan bahwa sebuah proses terdiri dari aktor, objek fisik dan objek informasi.

\section{Business process management (BPM)}

Dumas et al. (2018) menjabarkan bahwa BPM adalah satu kesatuan dari metode, teknik dan alat untuk mengidentifikasi, menemukan, menganalisis, mendesain, melaksanakan dan memonitor proses bisnis untuk mengoptimalisasi performa. BPM mengatur seluruh rantai kegiatan, aktivitas dan keputusan yang dapat menambah nilai suatu organisasi. BPM mampu membantu organisasi untuk mengurangi biaya, mengurangi waktu eksekusi dan mengurangi tingkat kesalahan. BPM lifecylcle dilihat sebagai putaran yang mana output dari monitoring phase kembali ke discovery phase, analysis dan redesign phase

\section{Model proses}

Model proses adalah urutan kegiatan yang dimodelkan dengan menggambarkan ketergantungan kasual (Aalst, 2016). Model proses mampu membantu organisasi dalam mengelola kompleksitas dengan memberikan wawasan dan mendokumentasikan prosedur (Aalst, 2016) juga memberikan transparansi pada para pemangku kepentingan (Rudnitckaia et al., 2019). Menurut penjabaran Aalst (2016), model proses digunakan untuk wawan, diskusi, dokumentasi, verifikasi, analisis performa, animasi, spesifikasi dan konfigurasi.

\section{Process discovery (Pada BPM lifecycle)}

Dumas et al. (2018) menjabarkan bahwa process discovery didefinisikan sebagai tindakan mengumpulkan informasi mengenai proses yang ada dan mengelola informasinya menjadi model proses yang sebenarnya terjadi. Metode automated process discovery (Metode discovery) merupakan salah satu metode pada process mining yang mampu menghasilkan model proses yang sebenarnya terjadi dengan mengolah data yang ada pada event log (Aalst, 2016). Automated process discovery dapat digunakan sebagai bagian dari process discovery pada BPM lifecycle (Dumas et al, 2018).

\section{E-learning}

Menurut penjabaran Clark \& Mayer (2016), e-learning adalah instruksi yang diberikan melalui perangkat digital (seperti komputer, laptop, tablet atau smart phone) yang ditujukan untuk mendukung pembelajaran. Materi yang diberikan pada $e-$ learning dapat berupa konten (sebagai informasi) dan metode pembelajaran yang membantu orang mempelajari konten. Materi $e-$ learning diberikan melalui perangkat digital dalam bentuk rangkaian kata tertulis maupun lisan dan gambar seperti ilustrasi, foto, animasi atau video. Pelajaran pada e-learning ditujukan untuk membantu orang yang belajar untuk mencapai tujuan pembelajarannya atau melakukan pekerjaannya dengan cara meningkatkan tujuan dasar organisasi.

\section{Kerangka Pemikiran}

Dari Gambar 1, kerangka pemikiran pada penelitian ini dapat djelaskan sebagai berikut:

1) User_id (case id) - merupakan kolom yang menunjukkan bagaimana tiap peristiwa berkorelasi (Aalst, 2016) atau objek yang mengatur urutan event log (Rudnitckaia J. , 2014). Pada pengaplikasiannya oleh IFLEX, kolom ini berisi 8 angka acak yang merujuk pada identitas tiap pengguna aplikasi IFLEX.

2) Activity - merupakan kolom yang berisi oleh kumpulan peristiwa (Aalst, 2016) atau kegiatan yang tercatat pada event log (Rudnitckaia J. , 2014). Pada pengaplikasiannya oleh IFLEX, kolom ini berisi aktifitas yang dilakukan oleh pengguna aplikasi IFLEX.

3) Timestamp - merupakan kolom yang berisi tanggal dan waktu yang berkaitan dengan peristiwa (Aalst, 2016) atau tanggal dan waktu yang direkam saat kegiatan berlangsung (Rudnitckaia J. , 2014). Pada pengaplikasiannya oleh IFLEX, kolom ini berisi tanggal dan waktu saat pengguna melakukan suatu kegiatan pada penggunaan aplikasi IFLEX. 

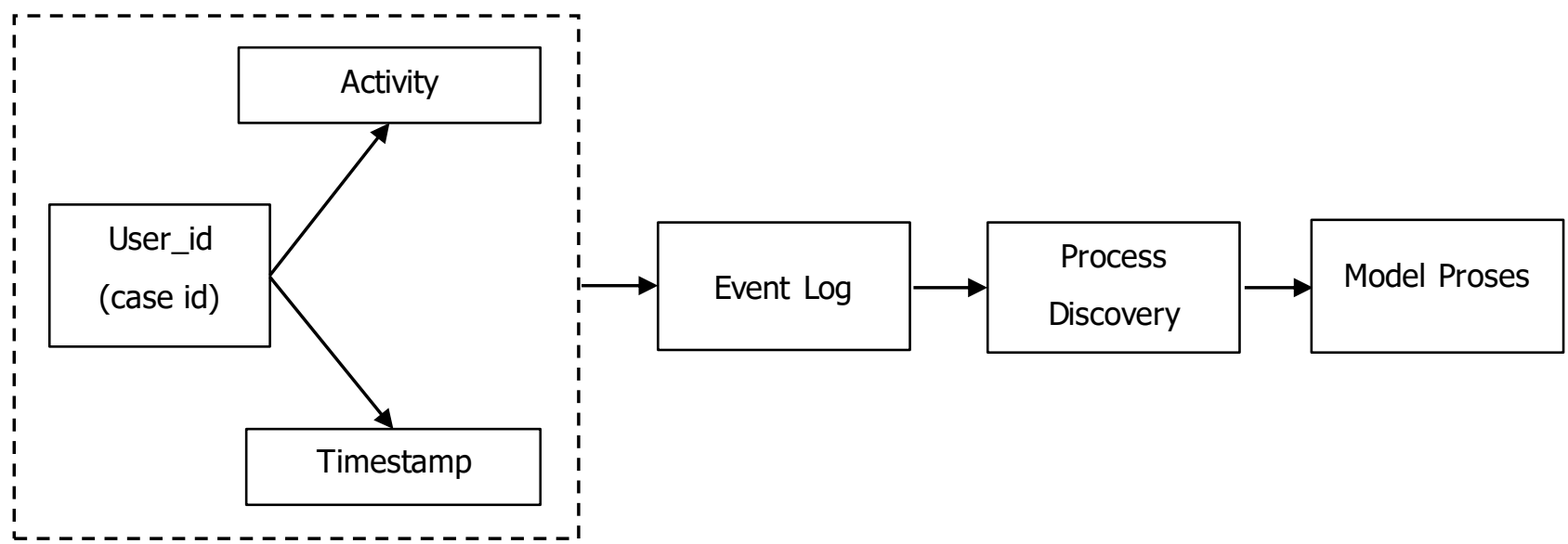

Gambar 1

Kerangka Pemikiran

4) Event log - merupakan kumpulan kasus yang mana tiap kasus terdiri dari beberapa peristiwa dengan atribut dapat berupa kegiatan, waktu, biaya dan sumber daya (Aalst, 2016). Pada pengaplikasiannya oleh IFLEX, atribut yang digunakan berupa kegiatan (Activity) dan waktu (Timestamp). Penulis menggunakan data dari event log milik IFLEX lalu diinput untuk mengasilkan model proses yang sebenarnya.

5) Process discovery - mengolah event log untuk menghasilkan model proses yang sebenarnya terjadi (Aalst, 2016). Penulis melakukan process discovery menggunakan event log yang dimiliki IFLEX untuk menghasilkan model proses yang sebenarnya pada aplikasi IFLEX.

6) Model proses - merupakan deskripsi logis dan grafis dari proses bisnis yang sebenarnya terjadi yang digunakan untuk menganalisis dan memperbaiki proses (Wang \& Sun, 2010). Pada penelitian ini, penulis ingin mendapatkan model proses pra-login/pra-register IFLEX

\section{Metode Penelitian}

Penelitian ini menggunakan metode kualitatif dengan tujuan penelitian berupa penelitian eksploratif. Unit analisis yang dipilih merupakan data aktivitas yang terekam selama periode sprint 1, yaitu sebanyak 563 aktivitas dengan 43 case id (User_id). Berdasarkan latar penelitian, penulis menggolongkan penelitian sebagai noncontrived setting. Berdasarkan waktu penelitian, penulis menggolongkan penelitian sebagai cross sectional karena pengambilan data hanya dilakukan pada satu periode terhitung dari tanggal 13 Maret 2020 hingga 13 April 2020. Penulis menggunakan sumber data sekunder yang berasal dari IFLEX dan menetapkan seluruh data event log IFLEX pada penerapan hasil sprint 1 yang penggunanya merupakan karyawan Telkom Medan sebagai populasi untuk penelitian ini. Penulis menentukan sampling yang digunakan berupa sampling jenuh atau dengan nama lain adalah sensus karena semua data pada populasi akan diolah.

\section{Teknik analisis data}

Penelitian dilakukan dengan menggunakan teknik proces mining. Process mining merupakan teknik analisis yang digunakan untuk mencari, memonitor dan memperbaiki proses yang sebenarnya terjadi dengan mengolah data dari event log (Aalst, 2016). Event log merupakan kumpulan kasus yang mana tiap kasus terdiri dari beberapa peristiwa dengan atribut dapat berupa kegiatan, waktu, biaya dan sumber daya (Aalst, 2016). Process mining merupakan jembatan antara process science dan data science atau dengan cara lain dapat dj̈elaskan bahwa process mining mencari konfrontasi antara data peristiwa dan model proses. Terdapat tiga metode pada process mining, yaitu: Discovery; conformance dan enhancement (Aalst, 2016). Pada penelitian ini, metode yang akan digunakan adalah discovery.

Metode discovery mengolah event log dan menghasilkan model proses tanpa minggunakan informasi a-priori (Aalst, 2016). 
Metode discovery yang menggunakan konsep play-in yang bertujuan untuk menciptakan model proses dari rekaman data peristiwa pada event log. Dalam artian lain, model proses yang didapat merupakan model proses yang mengilustrasikan peristiwa yang sebenarnya terjadi yang terekam pada event log. Menurut Aalst et al. pada Rudnitckaia et al. (2019) model proses yang dihasilkan oleh metode discovery mampu memberikan informasi berupa hambatan pada proses (bottleneck), penundaan dan penyimpangan proses. Terdapat beberapa algoritma yang sering digunakan untuk melakukan metode discovery, diantaranya: alpha-mining, heuristic mining, fuzzy mining dan inductive mining

Fuzzy mining adalah salah satu algoritma yang sering digunakan untuk melakukan metode discovery. Fuzzy mining memiliki hubungan dengan heuristic mining yang bertujuan untuk mengekstrak proses yang kurang terstruktur dan kompleks (Rudnitckaia et al., 2019). Dengan itu, algoritma ini mampu menghasilkan model proses yang lebih mudah untuk dimengerti.

\section{Langkah analisis}

\section{Pengumpulan data}

Data diambil bersumber dari event log IFLEX pada penerapan hasil sprint 1 yang penggunanya merupakan karyawan Telkom Medan dari tanggal 13 Maret 2020 hingga 13 April 2020. Data yang ada pada event log merupakan sekumpulan data peristiwa pada aplikasi IFLEX dengan atribut user_id, activity, page dan timestamp. Event log pada IFLEX akan berupa tabel berformat .csv.

\section{Data preprocessing}

Sebelum data diolah untuk menghasilkan model proses, data harus melewati tahap data pre-processing karena data yang didapatkan merupakan data mentah yang belum terstruktur dengan rapi dan terdapat banyak noise. Tahap ini dilakukan agar format data yang digunakan dapat diolah oleh tools yang digunakan saat analisis. Menurut Kouzari dan Stamelos (2018), agar bisa mendapatkan format data yang sesuai untuk process mining, dapat dilakukan pembersihan data (Data cleansing) dan transformasi data (Data transformation). Dari tahap tersebut, dihasilkan data event logi dengan atribut user id, activity dan timestamp.

\section{Process discovery}

Pada proses ini, data event log yang telah melalui tahap pre-processing selanjutnya diolah untuk menghasilkan model proses. Data diproses menggunakan algoritma fuzzy mining menggunakan aplikasi Celonis. Fuzzy mining memiliki hubungan dengan heuristic mining yang bertujuan untuk mengekstrak proses yang kurang terstruktur dan kompleks (Rudnitckaia et al., 2019). Sebagai hasilnya, fuzzy mining mampu menciptakan model proses yang mudah dimengerti. Untuk menghasilkan visualisasi model proses yang dapat mempermudah analisa, dapat dilakukan fittering data, adjusting connections dan adjusting activities.

\section{Analisis model proses}

Pada penelitian ini hasil visualisasi model proses dianalisa melalui rangkaian aktivitas yang dilakukan pengguna selama proses pra-login /pra-register. Analisa dilakukan dengan mempelajari aktivitas user berdasarkan frekuensi pengguna (Case frequency) dan durasi pengerjaan (Median throughput time) untuk menjawab keseluruhan pertanyaan penelitian.

\section{Hasil Penelitian \\ Process model discovery}

Tabel 1

Case Frequency

\begin{tabular}{|c|c|c|c|}
\hline No & Process Start & $\begin{array}{c}\text { Cases } \\
(\%)\end{array}$ & $\begin{array}{c}\text { Case } \\
\text { count }\end{array}$ \\
\hline 1 & Onboarding 1 & $60 \%$ & 26 \\
\hline 2 & Group List & $35 \%$ & 15 \\
\hline 3 & Lainnya & $5 \%$ & 2 \\
\hline \multicolumn{2}{|c|}{ Total } & $100 \%$ & 43 \\
\hline
\end{tabular}

Tabel 1 menjelaskan jumlah case berdasarkan aktivitas pemulaan yang dilalui pengguna setelah seluruh data event log diolah oleh celonis snap. Karena penelitian ini berfokus pada proses pra-login/pra-register, maka penulis melakukan penyaringan pada proses dengan memilih proses yang dimulai 
dari aktivitas onboarding 1 dengan jumlah 26 case yang merupakan ciri-ciri pra-login/praregister. Penyaringan tersebut akan menghasilkan model proses yang terfokus pada proses $\mathrm{pra}$-login/pra-register.

Error! Reference source not found. merupakan model proses yang sudah disaring menjadi 26 case (382 aktivitas) dan ditampilkan dengan struktur paling kompleks yang biasa disebut dengan spaghetti processes. Model proses tersebut dihasilkan dari rasio activities dan connections sebesar $100 \%$. Model proses ini mencakup keseluruhan aktivitas dan rute yang menggambarkan proses yang sebenarnya terjadi namun sulit untuk dipahami.

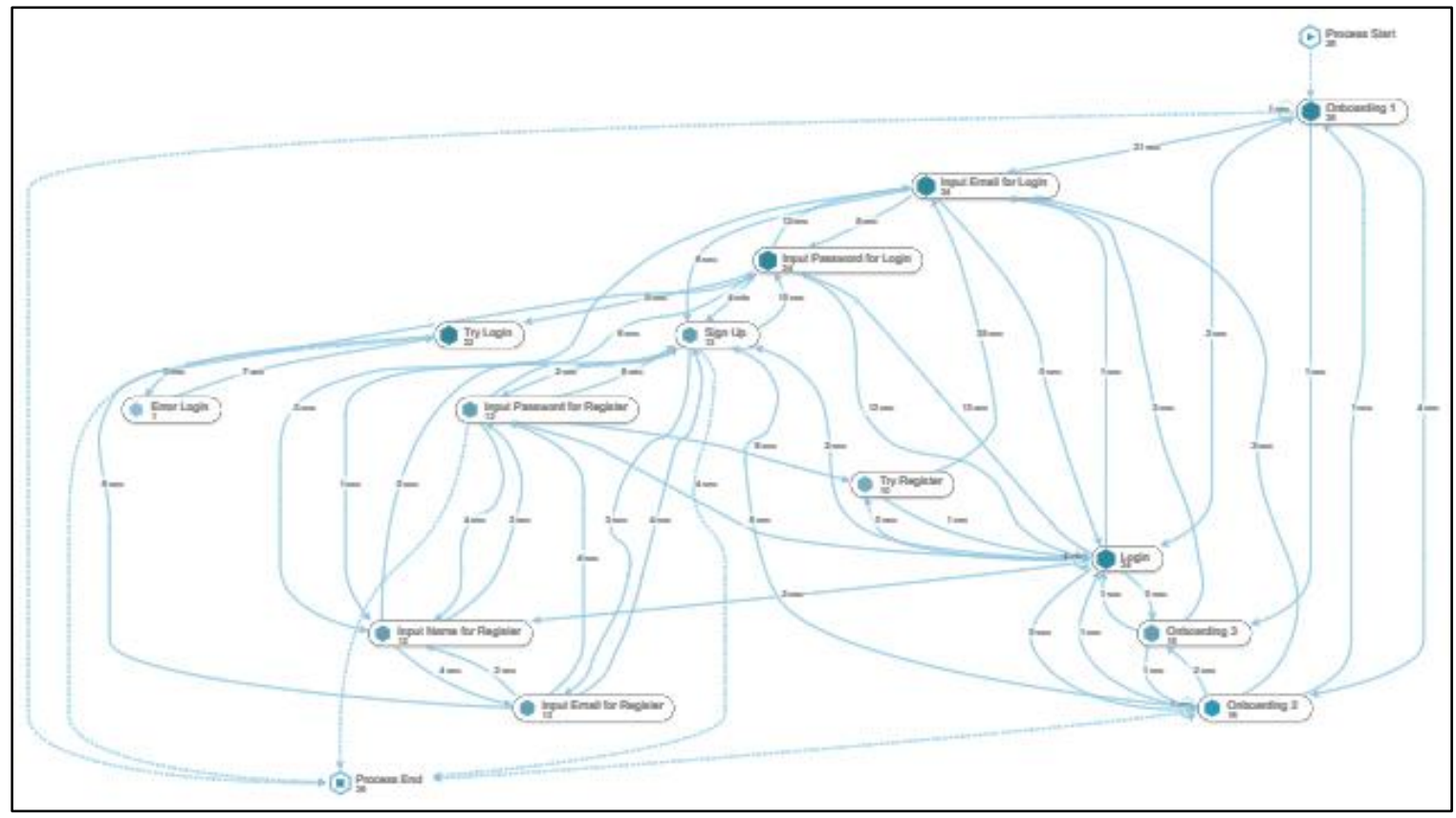

Gambar 2

Spaghetti Process

\section{Aktivitas pengguna}

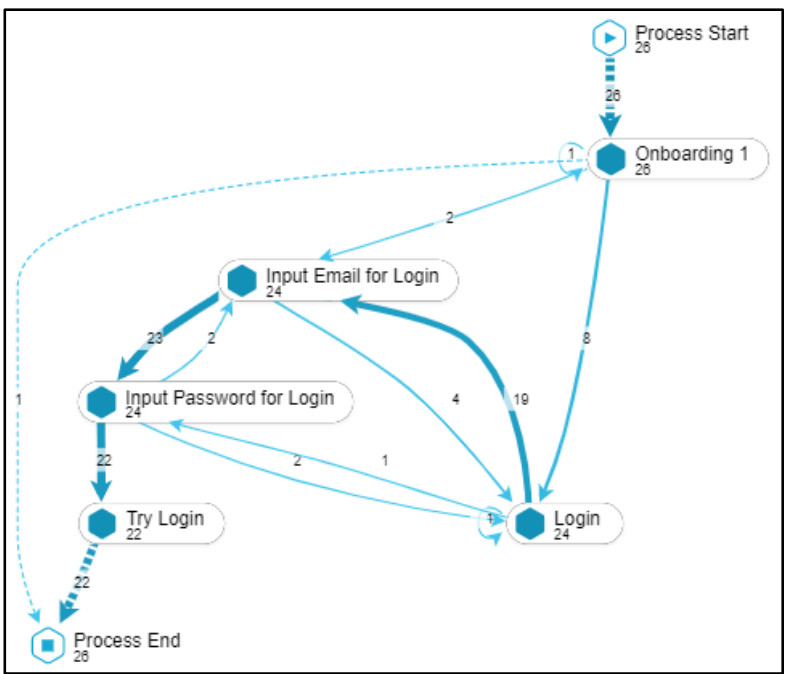

Gambar 2

Model Proses Dengan Rasio Activities 0\% dan Connections $100 \%$

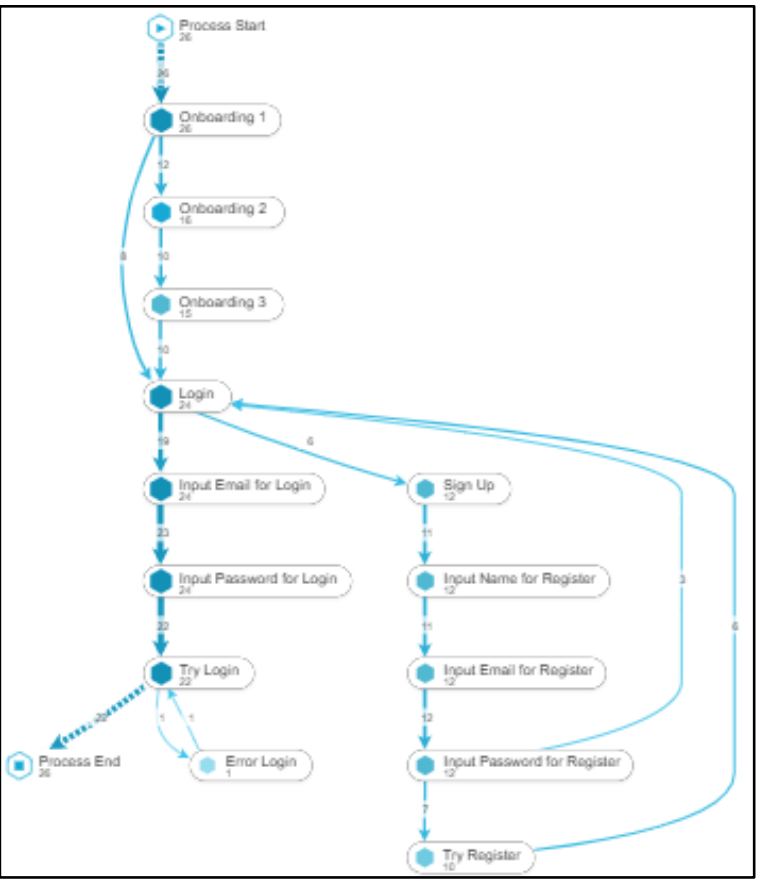

Gambar 3

Model Proses Dengan Rasio Activities 100\% dan Connections 0\% 
Pada model proses yang ada di Gambar 2 , penulis mengatur rasio activities menjadi $0 \%$ dan rasio connection menjadi $100 \%$ untuk melihat aktivitas utama dengan keseluruhan rute antar aktivitas pada proses. Penulis juga menggunakan indikator case frequency untuk mempermudah penulis memahami banyaknya pengguna (case) yang melewati tiap aktivitas pada proses tersebut. Terdapat 5 aktivitas yang paling umum dilalui pengguna pada proses, yaitu dimulai dari aktivitas onboarding 1 lalu secara berurutan lanjut ke aktivitas login, input email for login, input password for login dan terakhir try login. Selain itu terlihat satu pengguna yang langsung mengakhiri proses ketika baru saja memulai proses pada aktivitas onboarding 1.

Setelah itu penulis mengganti rasio activities menjadi $100 \%$ dan rasio connections $0 \%$ untuk melihat rute yang paling sering

dilalui pengguna dari seluruh rangkaian aktivitas pada proses tersebut. Dapat dilihat pada Gambar 3 bahwa terdapat 13 aktivitas yang terbagi menjadi tiga subproses, yaitu:

1) Perkenalan aplikasi melalui tiga halaman onboarding.

2) Register dengan mengisi tiga form yaitu nama, e-maildan password

3) Login dengan mengisi dua form yaitu username dan password.

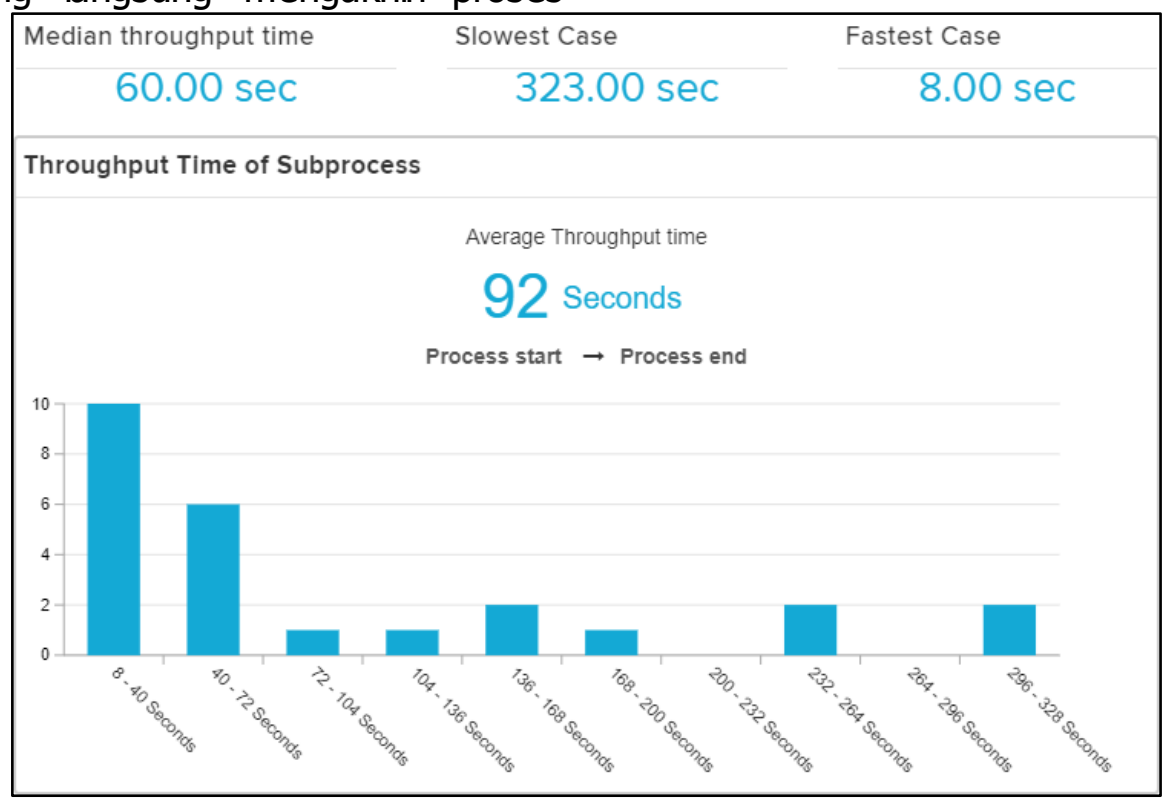

Gambar 4

Grafik Waktu Proses Pra-login/Pra-register

\section{Waktu pada proses}

Grafik waktu pada Error! Reference source not found. hanya mencatat berdasarkan 25 pengguna, bukan 26 pengguna, karena terdapat satu pengguna yang langsung mengakhiri proses pada saat memulai aktivitas. Dapat diketahui bahwa kumpulan waktu tersebut memiliki nilai tengah 60 detik. Waktu paling lama yang dibutuhkan oleh pengguna untuk menyelesaikan proses tersebut adalah 323 detik sedangkan yang tercepat adalah 8 detik. Rata-rata waktu yang pengguna butuhkan untuk menyelesaikan proses tersebut adalah 92 detik. Jika dibandingkan dengan grafik, dapat diketahui bahwa sebanyak 17 pengguna mampu menyelesaikan proses lebih cepat dari waktu rata-rata sementara 8 pengguna lainnya menyelesaikan proses lebih lama dari waktu rata-rata. Namun jika ditelaah kembali, pengguna yang harus melewati subproses

register memang membutuhkan waktu lebih lama dibandingkan mereka yang bisa

langsung melakukan subproses login. Maka dari itu penulis melakukan penelitian lebih detail terhadap waktu berdasarkan tiap subproses.

\section{Hambatan}

1. Subproses Perkenalan Aplikasi

Penilaian durasi aktivitas pada proses perkenalan aplikasi dilihat dari target minimum dan maksimum durasi yang ditentukan oleh tim IFLEX. Proses edukasi yang terlalu cepat, yaitu 
di bawah target minimum, tidak baik dan mengakibatkan pengguna tidak paham tentang manfaat aplikasi IFLEX. Hal ini bisa berdampak pada penggunaan selanjutnya yaitu pengguna bisa kebingungan dalam menggunakan aplikasi atau menyalahgunakan aplikasi. Sedangkan target maksimum ditentukan untuk mengukur apakah pengguna kebingungan dalam mencerna informasi yang disampaikan pada rangkaian aktivitas onboarding.

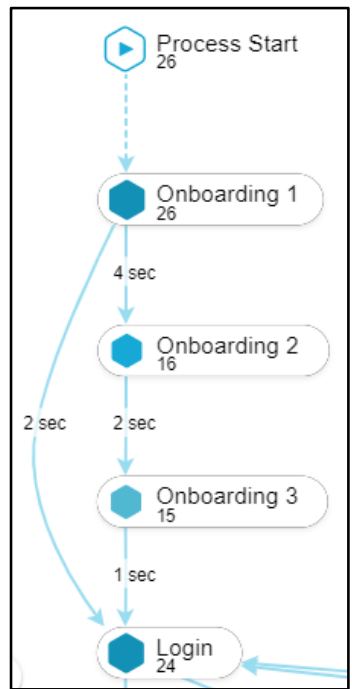

Gambar 5

Subproses perkenalan aplikasi

Tabel 2

Durasi Aktivitas Subproses Perkenalan Aplikasi Dibandingkan Dengan Target

\begin{tabular}{|l|c|c|c|c|}
\hline A ktivitas & $\begin{array}{c}\text { Target } \\
\text { min } \\
\text { (detik) }\end{array}$ & $\begin{array}{c}\text { Target } \\
\text { max } \\
\text { (detik) }\end{array}$ & \multicolumn{1}{c|}{$\begin{array}{c}\text { Realisasi } \\
\text { (detik) }\end{array}$} & Compliance \\
\hline $\begin{array}{l}\text { Onboarding } \\
\mathbf{1}\end{array}$ & 2 & 3 & 4 & $\begin{array}{c}\text { Not } \\
\text { comply }\end{array}$ \\
\hline $\begin{array}{l}\text { Onboarding } \\
\mathbf{2}\end{array}$ & 2 & 3 & 2 & Comply \\
\hline $\begin{array}{l}\text { Onboarding } \\
\mathbf{3}\end{array}$ & 2 & 3 & 1 & $\begin{array}{c}\text { Not } \\
\text { comply }\end{array}$ \\
\hline \hline TOTAL & $\mathbf{6}$ & $\mathbf{9}$ & $\mathbf{7}$ & Comply \\
\hline
\end{tabular}

Gambar 5 dan Tabel 2 merupakan perbandingan durasi pada subproses perkenalan aplikasi melalui rangkaian halaman onboarding dan target durasi. Dari penilaian target minimum dan maksimum didapatkan bahwa pengguna terlalu lama di aktivitas onboarding 1 yang melebihi target maksimum. Sedangkan durasi di aktivitas onboarding 2 sesuai dengan target yang ditentukan. Aktivitas onboarding 3 dinyatakan not comply karena pengguna terlalu cepat pada aktivitas tersebut.
Dari 26 pengguna di aktivitas onboarding 1 terdapat delapan pengguna yang memilih untuk tidak melalui rangkaian aktivitas onboarding 2 dan onboarding 3 dan langsung ke aktivitas login seperti pada Gambar 5. Delapan pengguna ini menghabiskan waktu dua detik di onboarding 1. Durasi ini memenuhi target minimum namun mereka tidak teredukasi dengan baik karena melewati rangkaian aktivitas perkenalan pada onboarding. Dari sini juga dapat diketahui bahwa rangkaian aktivitas onboarding 2 dan onboarding 3 merupakan rangkaian aktivitas yang tidak perlu dilalui untuk bisa melanjutkan ke aktivitas selanjutnya walaupun sebenarnya semua rangkaian onboarding penting untuk dilalui sebagai media edukasi pengguna dalam menggunakan aplikasi IFLEX.

Pada subproses ini perlu dicari tahu beberapa hal terkait penyebab durasi pengguna yang terlalu lama pada aktivitas onboarding 1 dan terlalu cepat pada aktivitas onboarding 3 juga mengapa beberapa pengguna memilih untuk tidak melalui rangkaian onboarding melalui penelitian lainnya diluar penelitian ini.

\section{Subproses Register}

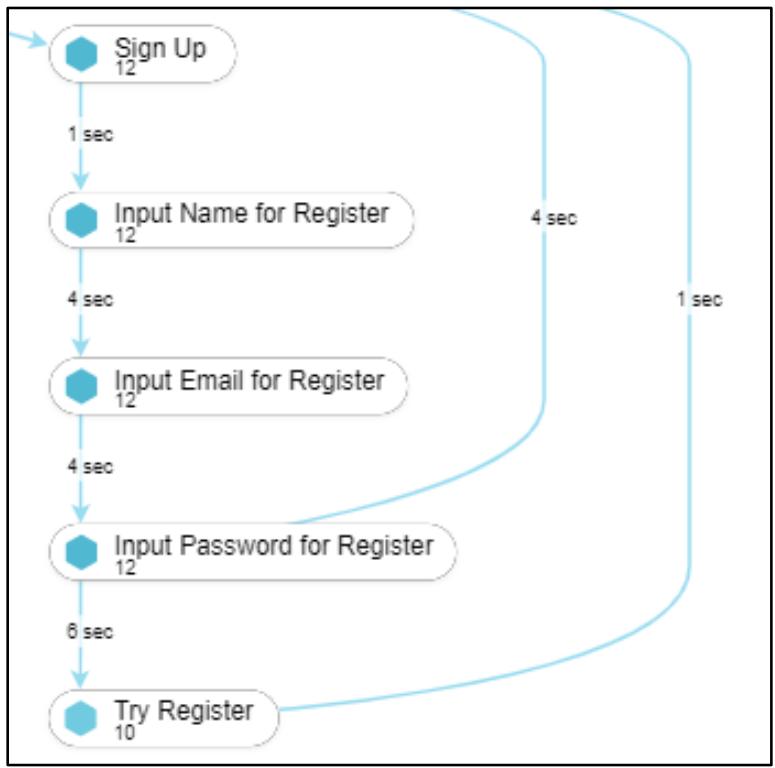

Gambar 6

Subproses Register 
Tabel 3

Perbandingan Durasi Subproses Register

Terhadap Target (Lebih Cepat, Lebih Baik)

\begin{tabular}{lccc}
\hline Aktivitas & $\begin{array}{c}\text { Target } \\
\text { (detik) }\end{array}$ & $\begin{array}{c}\text { Realisasi } \\
\text { (detik) }\end{array}$ & $\begin{array}{c}\text { Ach } \\
\text { (\%) }\end{array}$ \\
\hline $\begin{array}{l}\text { Signup } \\
\text { Input }\end{array}$ & 1 & 1 & $100 \%$ \\
$\begin{array}{l}\text { name } \\
\text { Input } \\
\text { email }\end{array}$ & 4 & 4 & $100 \%$ \\
$\begin{array}{l}\text { Input } \\
\text { Password }\end{array}$ & 4 & 4 & $100 \%$ \\
$\begin{array}{l}\text { Try } \\
\text { Register } \\
\text { TOTAL }\end{array}$ & 1 & 6 & $67 \%$ \\
\hline
\end{tabular}

Gambar 6 dan

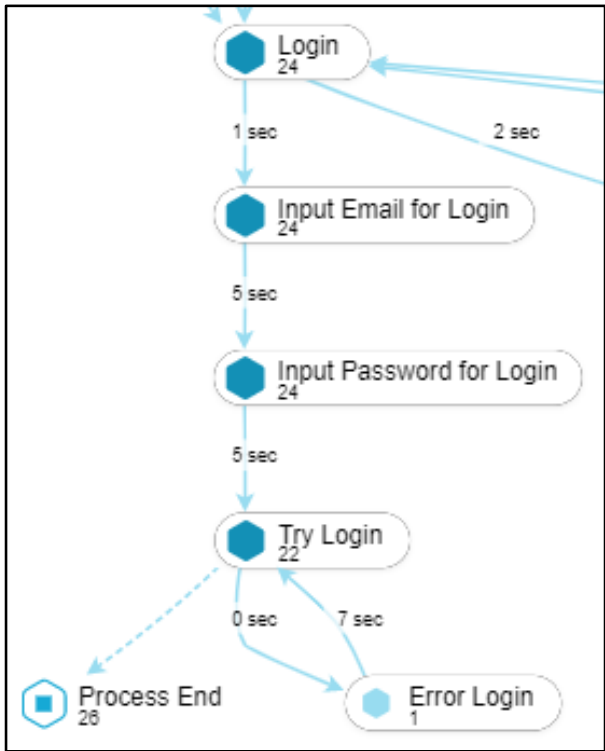

Gambar 7

Subproses Login

Tabel 4

Perbandingan Durasi Subproses Register Terhadap Target (Lebih Cepat, Lebih Baik)

\begin{tabular}{lccc}
\hline Aktivitas & $\begin{array}{c}\text { Target } \\
\text { (detik) }\end{array}$ & $\begin{array}{c}\text { Realisasi } \\
\text { (detik) }\end{array}$ & $\begin{array}{c}\text { Ach } \\
\text { (\%) }\end{array}$ \\
\hline Login & 1 & 1 & $100 \%$ \\
\hline $\begin{array}{l}\text { Input } \\
\text { email }\end{array}$ & 4 & 5 & $80 \%$ \\
$\begin{array}{l}\text { Input } \\
\text { password }\end{array}$ & 4 & 5 & $80 \%$ \\
$\begin{array}{l}\text { Try login } \\
\text { TOTAL }\end{array}$ & 1 & 0 & - \\
\hline
\end{tabular}

Pada proses login, terdapat dua aktivitas yang tidak memenuhi target, yaitu aktivitas input email dan input password. Perlu dilakukan penelitian lainnya untuk analisa lebih lanjut mengapa pengguna lama pada dua aktivitas tersebut. Selain itu, terdapat aktivitas error login yang menurut data berdurasi 7 detik. Aktivitas ini tidak memiliki target durasi karena bervariasinya penyebab error login.

\section{Simpulan}

Process mining dengan metode process discovery menggunakan aplikasi Celonis Snap dapat membantu IFLEX untuk mendapatkan model proses dan memahami proses yang sebenarnya terjadi pada proses pra-login/praregister IFLEX. Terdapat 5 aktivitas utama yang paling umum dilalui pengguna, yaitu dimulai dari aktivitas onboarding 1 lalu secara 
berurutan lanjut ke aktivitas login, input email for login, input password for login dan terakhir try login. Rata-rata waktu yang dihabiskan pengguna pada proses tersebut adalah 92 detik. Namun, karena adanya kemungkinan perbedaan waktu yang kontras antara pengguna yang perlu melalui subproses register dan yang tidak perlu melalui subproses register, maka diteliti lebih lanjut detail waktu tiap subproses. Proses pra-login/pra-register aplikasi IFLEX terdiri dari 3 rangkaian subproses, yaitu subproses perkenalan aplikasi, subproses register dan subproses login. Dari ketiga subproses tersebut, terdapat beberapa ketidaksesuaian durasi aktivitas terhadap target durasi aktivitas yang ditentukan IFLEX. Hal ini dapat dijadikan landasan untuk dilakukannya penelitian lebih lanjut agar menciptakan proses pra-login/pra-register aplikasi IFLEX yang efektif dan efisien

\section{Saran}

Dapat dilakukan process mining menggunakan metode yang berbeda, seperti conformance checking dan enhancement untuk mendapatkan informasi mengenai proses yang lebih dalam. Ada baiknya untuk menyediakan event log dengan atribut waktu sedetail mungkin seperti adanya milidetik untuk akurasi waktu dalam rangkaian aktivitas.

\section{Daftar Pustaka}

Aalst, W. v. (2016). Process Mining: Data Science in Action. Berlin: Springer. doi:10.1007/978-3-662-49851-4

Clark, R. C., \& Mayer, R. E. (2016). E-Learning and the Science of Instruction. New Jersey: John Wiley \& Sons.

Dogan, O. (2018). PROCESS MINING FOR CHECK-UP PROCESS ANALYSIS. ResearchGate, 56-61.

Dumas, M., Rosa, M. L., Mendling, J., \& Rej̈ers, H. A. (2018). Fundamentals of Business Process Management. Berlin: Springer. doi:10.1007/978-3-662-56509-4

IFLEX. (2019). Sidang Komite.
Indrawati. (2015). Metode Penelitian Manajemen dan Bisnis Konvergensi Teknologi Komunikasi dan Informasi. Bandung: PT Refika Aditama.

Juhanak, L., Zounek, J., \& Rohlikova, L. (2017). Using process mining to analyze students' quiz-taking behavior. patterns in a learning management system, 1-11. doi:https://doi.org/10.1016/j.chb.2017.1 2.015

K., G., S, D., \& M., S. R. (2017). An Approach to Fuzzy Process Mining to Reduce Patient Waiting Time in a Hospital. 2017 International Conference on Innovations in information Embedded and Communication Systems (ICIIECS) (hal. 1-6). Coimbatore: IEEE. doi:10.1109/ICIIECS.2017.8275889.

Kouzari, E., \& Stamelos, I. (2018). Process mining applied on library information systems: A case study. Elsevier. doi:doi:10.1016/j. lisr.2018.09.006

Osman, C. C., \& Ghiran, A. M. (2019). When Industry 4.0 meets Process Mining. 23rd International Conference on KnowledgeBased and Intelligent Information \& Engineering Systems (hal. 2130-2136). Romania:

Elsevier. doi:10.1016/j.procs.2019.09.386

Ramadan, S., Baqapuri, H. I., Roecher, E., \& Mathiak, K. (2019). Process mining of logged gaming behavior. 2019 International Conference on Process Mining (ICPM) (hal. 57-64). Aachen: IEEE. doi:10.1109/ICPM.2019.00019

Rudnitckaia, J. (2014). Process Mining. Data Science in Action. SemanticScholar.

Rudnitckaia, J., Intayoad, W., Becker, T., \& Hruska, T. (2019). Applying Process Mining to the Ship Handling. IEEE. doi:10.1109/ICPHYS.2019.8780305

Sekaran, U., \& Bougie, R. (2016). Research Methods for Business: $A$ Skill-Building 
Approach. Chichester: John Wiley \& Sons.

Sugiyono. (2017). Metode Penelitian Kuantitatif, Kualitatif dan R\&D. Bandung: ALFABETA.

Wang, M., \& Sun, Z. (2010). Handbook of Research on Complex Dynamic Process Management: Techniques for Adaptability in Turbulent Environments. Hershey: Business Science Reference. 